\title{
Association Of Periodontal Health Status with Crowding Of Dental Arches in Adults - A Retrospective Study
}

\author{
Research Article
}

Kadambari Sriram ${ }^{1}$, Ravindra Kumar Jain S², M.P. Santhosh Kumar ${ }^{3}$

${ }^{1}$ Saveetha Dental College and Hospitals, Saveetha Institute of Medical and Technical Sciences, Saveetha University, Chennai, India.

${ }^{2}$ Reader, Department of Orthodontics and Dentofacial Orthopedics, Saveetha Dental College and Hospitals, Saveetha Institute of Medical and Technical Sciences, Saveetha University, Chennai, 600077, India.

${ }^{3}$ Reader, Department of Oral and Maxillofacial Surgery, Saveetha Dental College and Hospitals, Saveetha Institute of Medical and Technical Sciences, Saveetha University, Chennai, 600077, India.

\section{Abstract}

\begin{abstract}
Malocclusion refers to the mal-relationship of the dental arches. Periodontitis is defined as an inflammatory disease of the supporting tissues of the teeth. Dental plaque is recognised as an essential precursor for periodontitis. Therefore any factor which is presumed to promote plaque retention or make its removal difficult can contribute to the risk of periodontal disease. The crowding of teeth creates areas hardly accessible for tooth brushing and makes oral hygiene measures very difficult.The aim of the study was to evaluate the association between periodontal health status with crowding of arches in adults. A retrospective study was carried out using digital records of patients who reported to a Dental hospital from June 2019 to March 2020. A total of 200 patients with moderate and severe crowding were included for the study evaluation. The age, gender, Gingival index scores, Plaque index scores, community periodontal index of treatment needs (CPITN) scores were observed from the digital records and tabulated on a spreadsheet. The collected data was analysed by computer software SPSS version 20. Chi square test was performed with the level of significance set at $5 \%$. Significant association between severity of malocclusion and periodontal health $(\mathrm{p}<0.05)$ was noted. No significant association was found between gender and severity of crowding ( $p>0.05)$. Within limits of the study significant association was found between severity of crowding and periodontal health.
\end{abstract}

Keywords: Crowding; Gingivitis; Malocclusion; Periodontitis.

\section{Introduction}

Malocclusion refers to the mal-relationship of the dental arches along with the anomalies in teeth positioning [1]. The etiology of malocclusion [2-4] can be classified as either Genetic, Environmental or Local [5]. Periodontitis is defined as an inflammatory disease of the supporting tissues of the teeth [6] caused by specific organisms or groups of specific organisms resulting in progressive destruction of the periodontal ligament and alveolar bone with periodontal pocket formation, gingival recession or both [7].

As the above statement claims the etiology and pathogenesis of periodontal disease is multifactorial but dental plaque is recognised as an essential precursor $[8,9]$. Therefore any factor $[10]$ which is presumed to promote plaque retention or make its removal difficult can contribute to the risk of periodontal disease. The crowding of teeth creates areas hardly accessible for tooth brushing and makes oral hygiene [11] measures very difficult [12].

Previous literature states that various types of malocclusions have also been correlated to increased plaque indices [13, 14]. In a study by Ainamo et al,it was found that the extent of periodontal disease was worse around malaligned teeth [15] than around aligned teeth [16]. Gusmao et al., found in their study that all tooth malpositions [17] lead to occlusal trauma $[18,19]$ which further lead to periodontal disease progression [20]. On the other hand, many other studies failed to demonstrate any significant correlation between tooth irregularity [21] and periodontal health [22, 23]. The aim of this study was to evaluate the association of periodontal

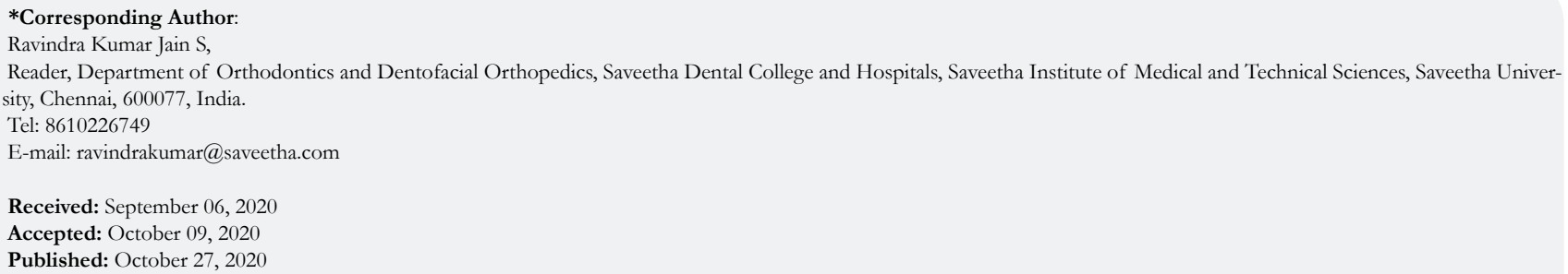

Copyright: Ravindra Kumar Jain S 2020 . This is an open-access article distributed under the terms of the Creative Commons Attribution License, which permits unrestricted use, distribution and reproduction in any medium, provided the original author and source are credited. 
health with the crowding of arches.

\section{Materials and Methods}

\section{Study Design}

In this retrospective study, data from 86000 patients reporting to a Dental Hospital were collected. To fulfil the inclusion criteria, patients above 18 years of age with presence of crowding were included in the study. 200 patients were selected for the study by random sampling, who fulfilled the inclusion criteria. Patients who were outside this age group or those with other systemic complications were excluded from the study. The study was commenced after approval from the scientific review board, and the ethical clearance was obtained from the ethical committee of the University with the following ethical approval number-SDC/ SIHEC/2020/DIASDATA/0619-0320.After data extraction, all information was anonymized and tabulated onto a spreadsheet.

\section{Subjects and Procedures}

It was a retrospective study. Data was collected from July 2019 to March 2020.

The following data were retrieved from the dental records: patient age, gender, Gingival index score, Plaque index score,community periodontal index of treatment needs (CPITN) scores and periodontal status. The records were examined for errors by photographic evaluation. Incomplete or censored data was excluded from the study.

\section{Statistical Analysis}

The statistical analysis was done using Statistical Package for Social Sciences for Windows, version 20.0 (SPSS Inc., Chicago, IL, USA). Independent variables included age, gender. Dependent variables included crowding, periodontal status. Chi-square test was used to compare the malocclusion and periodontal status of the patients. The significance level was set at $5 \%$ for the present study.

\section{Results and Discussion}

A total of 200 participants were included in the study of which $52 \%$ were female and $48 \%$ were males. $26.5 \%$ of the females in the study had severe crowding while $23.5 \%$ of the males had severe crowding (Figure 1). No significant association was found between severity of crowding and gender (Figure 1). Significant association was found between severity of crowding and periodontal status, $\mathrm{p}<0.05$, Chi square test.(Figure 2) $14 \%$ of the patients with severe crowding presented with periodontitis. $1.5 \%$ of the patients with moderate crowding had periodontitis.( Figure 2)

The association between gender and periodontal status was found to be significant, $\mathrm{p}<0.05$, Chi square test (Figure 3).

It was observed in the present study that there was significant association between the severity of crowding of the arches and the periodontal health status. The association between gender and periodontal health was found to be significant. The association between gender and the severity of crowding was not found to

Figure 1. Bar graph representing association of Gender and Severity of crowding, where $\mathrm{X}$ axis denotes both Genders (Male and Female) and $\mathrm{Y}$ axis denotes the number of patients with severity of crowding as; Moderate(blue), severe (Red).

Chi square association was done and found to be statistically not significant. Pearson Chi-Square value $=0.080 \mathrm{a}, \mathrm{df}=1, \mathrm{P}$ value $=.77, P>0.05$, not significant. Proving that gender does not influence the severity of crowding.

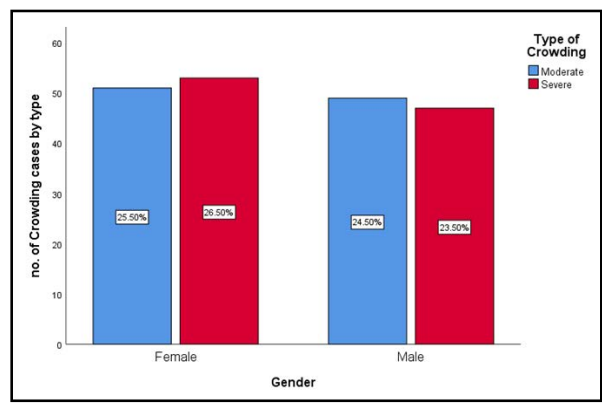

Figure 2. Bar graph representing association between periodontal status and the Severity of crowding, where $X$ axis denotes the type and severity of crowding (moderate and severe) and $\mathrm{Y}$ axis denotes the number of patients with different periodontal status. Chi square test was done and association was found to be statistically significant. Pearson Chi-Square value $=23.860 \mathrm{a}, \mathrm{df}=1, \mathrm{P}$ value $=0.00, \mathrm{P}<0.05$, significant. Proving moderate crowding was associated with gingivitis and severe crowding was associated with periodontitis.

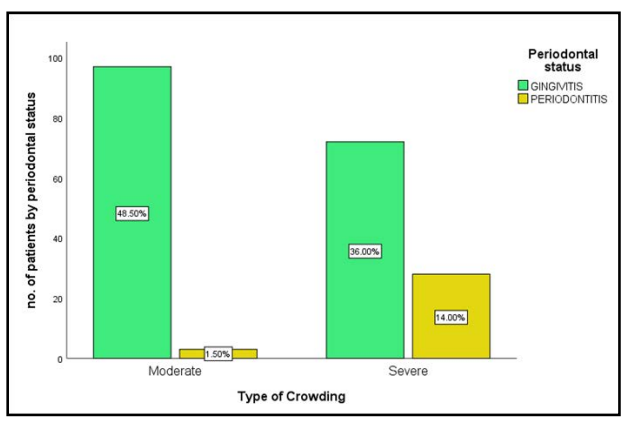


Figure 3. Bar graph depicting association between gender and periodontal status,where $\mathrm{X}$ axis denotes both Genders (Male and Female) and $\mathrm{Y}$ axis denotes the number of patients with different periodontal status: periodontitis (Yellow) and gingivitis (green). Chi-square test was done and the association was found to be statistically significant. Pearson Chi-Square value $=4.009 \mathrm{a}, \mathrm{df}=1, \mathrm{P}$ value $=0.04, \mathrm{P}<0.05$, significant. Proving that gender is associated with periodontal status and periodontitis was more common in males compared to females.

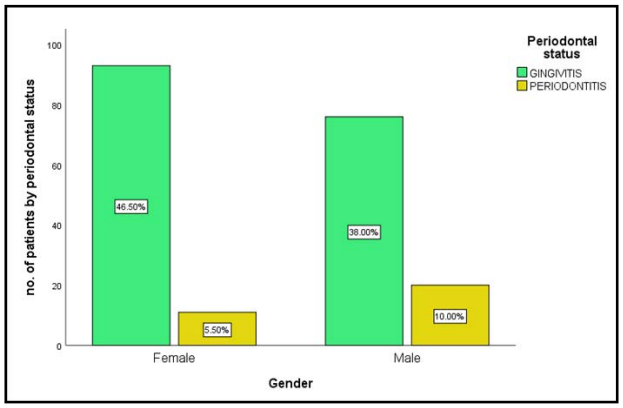

Table 1. Table depicting the Gender wise distribution (Male and Female) of severity of crowding (severe and moderate)

Females (53) appear to have more prevalence of severe crowding than males (47).

\begin{tabular}{|c|c|c|c|c|}
\hline \multicolumn{4}{|c|}{ Gender wise distribution of Crowding } \\
\hline \multirow{2}{*}{} & \multicolumn{2}{|c|}{ Type of Crowding } & \multirow{2}{*}{ Total } \\
\cline { 3 - 4 } \multicolumn{2}{|c|}{ Gender } & Mederate & Severe & \\
\cline { 2 - 4 } & Male & 51 & 53 & 104 \\
\hline \multicolumn{2}{|c|}{ Total } & 100 & 49 & 96 \\
\hline \multicolumn{2}{|c|}{ Tote } & 100 & 200 \\
\hline
\end{tabular}

Table 2. Table depicting the periodontal status(periodontitis and gingivitis) distribution by Severity of crowding(severe and moderate). Higher prevalence of periodontitis was observed in severe crowding cases(28) than moderate crowding(3).

\begin{tabular}{|c|c|c|c|c|}
\hline \multicolumn{4}{|c|}{ Periodontal status by Type of Crowding } \\
\hline & \multicolumn{2}{|c|}{ Periodontal status } & \multirow{2}{*}{ Total } \\
\cline { 3 - 5 } \multicolumn{2}{|c|}{} & GINGIVITIS & PERIODONTITIS & \\
\hline \multirow{2}{*}{$\begin{array}{c}\text { Type of } \\
\text { Crowding }\end{array}$} & Moderate & 97 & 3 & 100 \\
\cline { 2 - 4 } & Severe & 72 & 28 & 100 \\
\hline \multicolumn{2}{|c|}{ Total } & 169 & 31 & 200 \\
\hline
\end{tabular}

Table 3. Table depicting the Gender wise distribution (Male and Female) of periodontal status(periodontitis and gingivitis). Males(20) appear to have more prevalence of periodontitis than Females (11).

\begin{tabular}{|c|c|c|c|c|}
\hline \multicolumn{4}{|c|}{ Gender wise distribution of Periodontal status } \\
\hline \multirow{2}{*}{} & \multicolumn{3}{c|}{ Periodontal status } & \multirow{2}{*}{ Total } \\
\cline { 3 - 5 } \multicolumn{2}{|c|}{ GINGIVITIS } & PERIODONTITIS & \\
\hline \multirow{3}{*}{ Gender } & Female & 93 & 11 & 104 \\
\cline { 2 - 5 } & Male & 76 & 20 & 96 \\
\hline \multicolumn{2}{|c|}{ Total } & 169 & 31 & 200 \\
\hline
\end{tabular}

be significant.

Significant association was found between the severity of crowding of the arches and the periodontal health. However while some previous studies have discussed that improper occlusal forces [18, 24-26] due to malalignment can progress to pocket formation [27, 28], other studies have found evidence of association weak and inconsistent [29]. The reported relationships between crowding and periodontal status have ranged from no relationship [30, 31], to a weak relationship [32]. The associations between crowding and oral hygiene performance along with chronic periodontitis have also been reported as weak [33]. Significant association was found between gender and periodontal health. These findings are consistent with the findings of Helm et al, which states that men are at greater risk for periodontal disease than women [34]. No significant association was found between gender and the severity of crowding. This finding is consistent with findings of Rahbar et al,2010 and Decusara et al,2019, which state that even though males have higher interarch and intra arch dimensions than females, there was no significant difference in the severity of crowding $[35,36]$. 
The limitations of the study include that it has a limited sample size as it is a single centre study. The future scope of the study can involve expanding it to a multicentre study and taking the classification of dental crowding into consideration.

\section{Conclusion}

Within the limits of the current study significant associations were found between the crowding of the dental arches and periodontal health status. Severe crowding of the dental arches was associated with more periodontal breakdown. A larger number of male subjects had severe crowding and periodontitis than females, whereas more females presented with moderate crowding than males hence gingivitis was more common among females.

\section{Acknowledgements}

The authors of this study would like to express their gratitude towards everyone who facilitated and enabled us to carry out this study successfully. We would also thank the institute for helping us to have access to all the case records for collecting the required cases for conducting this study.

\section{Authors Contribution}

Kadambari Sriram contributed to the acquisition of data, analysis, literature collection, and in drafting the article and revising it critically for important intellectual content. Ravindra kumar Jain contributed in conception, study design, interpretation of data, formatting, manuscript preparation, supervision and guidance. Santhosh Kumar contributed to the editing, supervision and final approval of the submitted version of the manuscript.

\section{References}

[1]. Housten W. Walther's orthodontic notes.(4thedn) The Stonebridge Publishers. United States. 2000;

[2]. Rubika J, Felicita AS, Sivambiga V. Gonial angle as an indicator for the prediction of growth pattern. World J Dent. 2015;6(3):161-3.

[3]. Felicita AS, Chandrasekar S, Shanthasundari KK. Determination of craniofacial relation among the subethnic Indian population: a modified approach - (Sagittal relation). Indian J Dent Res. 2012 May-Jun;23(3):305-12. Pubmed PMID: 23059564

[4]. Felicita AS. Orthodontic management of a dilacerated central incisor and partially impacted canine with unilateral extraction - A case report. Saudi Dent J. 2017 Oct;29(4):185-193.Pubmed PMID: 29033530.

[5]. Littlewood SJ, Mitchell L. An introduction to orthodontics. Oxford university press; 2019 Mar 16:408.

[6]. Samantha C, Sundari S, Chandrasekhar S, Sivamurty G, Dinesh S. Comparative Evaluation of Two Bis-GMA Based Orthodontic Bonding Adhesives - A Randomized Clinical Trial. J ClinDiagn Res. 2017 Apr;11(4):ZC40ZC44.Pubmed PMID: 28571259.

[7]. Newman MG, Takei H, Klokkevold PR, Carranza FA. Carranza's clinical periodontology. Elsevier health sciences; $2011 \mathrm{Feb}$ 14:872.

[8]. Axelsson P, Lindhe J. The effect of a preventive programme on dental plaque, gingivitis and caries in schoolchildren. Results after one and two years. J ClinPeriodontol. 1974;1(2):126-38.Pubmed PMID: 4532119.

[9]. Socransky SS. Relationship of bacteria to the etiology of periodontal disease. J Dent Res. 1970 Feb;49(2):203-22.

[10]. Viswanath A, Ramamurthy J, Dinesh SP, Srinivas A. Obstructive sleep apnea: awakening the hidden truth. Niger J ClinPract. 2015 Jan-Feb;18(1):1-7. Pubmed PMID: 25511335

[11]. Kamisetty SK, Verma JK, Arun, Sundari S, Chandrasekhar S, Kumar A. SBS vsInhouse Recycling Methods-An Invitro Evaluation. J ClinDiagn Res. 2015 Sep;9(9):ZC04-8.Pubmed PMID: 26501002.

[12]. Addy M, Griffiths GS, Dummer PM, Kingdon A, Hicks R, Hunter ML, et al.The association between tooth irregularity and plaque accumula- tion, gingivitis, and caries in 11-12-year-old children. Eur J Orthod. 1988 Feb;10(1):76-83.Pubmed PMID: 3162883.

[13]. Ashley FP, Usiskin LA, Wilson RF, Wagaiyu E. The relationship between irregularity of the incisor teeth, plaque, and gingivitis: a study in a group of schoolchildren aged 11-14 years. Eur J Orthod. 1998 Feb;20(1):65-72. Pubmed PMID: 9558766.

[14]. Buckley LA. The relationships between malocclusion, gingival inflammation, plaque and calculus. J Periodontol. 1981 Jan;52(1):35-40.Pubmed PMID: 6937649.

[15]. Ramesh Kumar KR, ShantaSundari KK, Venkatesan A, Chandrasekar S. Depth of resin penetration into enamel with 3 types of enamel conditioning methods: a confocal microscopic study. Am J OrthodDentofacialOrthop. 2011 Oct;140(4):479-85.Pubmed PMID: 21967934.

[16]. Ainamo J. Relationship between malalignment of the teeth and periodontal disease. Scand J Dent Res. 1972;80(2):104-10.

[17]. Felicita AS. Orthodontic extrusion of Ellis Class VIII fracture of maxillary lateral incisor - The sling shot method. Saudi Dent J. 2018 Jul;30(3):265269. Pubmed PMID: 29942113.

[18]. Krishnan S, Pandian S, Kumar S A. Effect of bisphosphonates on orthodontic tooth movement-an update. J ClinDiagn Res. 2015 Apr;9(4):ZE01-5. Pubmed PMID: 26023659.

[19]. Dinesh SP, Arun AV, Sundari KK, Samantha C, Ambika K. An indigenously designed apparatus for measuring orthodontic force. J ClinDiagn Res. 2013 Nov;7(11):2623-6.Pubmed PMID: 24392423.

[20]. Gusmão ES, Queiroz RD, Coelho RD, Cimōes R, Santos RL. Association between malpositioned teeth and periodontal disease. Dental Press J Orthod. 2011 Aug; 16(4):87-94.

[21]. Vikram NR, Prabhakar R, Kumar SA, Karthikeyan MK, Saravanan R. Ball Headed Mini Implant. J ClinDiagn Res. 2017 Jan;11(1):ZL02-3.

[22]. Ingervall B, Jacobsson U, Nyman S. A clinical study of the relationship between crowding of teeth, plaque and gingival condition. J ClinPeriodontol. 1977 Aug;4(3):214-22.Pubmed PMID: 268334.

[23]. Samantha C, Sundari S, Chandrasekhar S, Sivamurty G, Dinesh S. Comparative Evaluation of Two Bis-GMA Based Orthodontic Bonding Adhesives - A Randomized Clinical Trial. J ClinDiagn Res. 2017 Apr;11(4):ZC40ZC44.Pubmed PMID: 28571259.

[24]. Sivamurthy G, Sundari S. Stress distribution patterns at mini-implant site during retraction and intrusion--a three-dimensional finite element study. ProgOrthod. 2016 Jan 18;17(1):4.Pubmed PMID: 26780464.

[25]. Felicita AS. Quantification of intrusive/retraction force and moment generated during en-masse retraction of maxillary anterior teeth using mini-implants: A conceptual approach. Dental Press J Orthod. 2017 SepOct;22(5):47-55.Pubmed PMID: 29160344.

[26]. Jain RK, Kumar SP, Manjula WS. Comparison of intrusion effects on maxillary incisors among mini implant anchorage, $\mathrm{j}$-hook headgear and utility arch. J Clin Diagn Res. 2014 Jul;8(7):ZC21-4.Pubmed PMID: 25177631.

[27]. Burgett FG, Ramfjord SP, Nissle RR, Morrison EC, Charbeneau TD, Caffesse RG. A randomized trial of occlusal adjustment in the treatment of periodontitis patients. J ClinPeriodontol. 1992 Jul;19(6):381-7.Pubmed PMID: 1634627.

[28]. Nunn ME, Harrel SK. The effect of occlusal discrepancies on periodontitis. I. Relationship of initial occlusal discrepancies to initial clinical parameters. J Periodontol. 2001 Apr;72(4):485-94.

[29]. Bollen AM, Cunha-Cruz J, Bakko DW, Huang GJ, Hujoel PP. The effects of orthodontic therapy on periodontal health: a systematic review of controlled evidence. J Am Dent Assoc. 2008 Apr 1;139(4):413-22.

[30]. Onyeaso CO, Arowojolu MO, Taiwo JO. Periodontal status of orthodontic patients and the relationship between dental aesthetic index and community periodontal index of treatment need. Am J OrthodDentofacialOrthop. 2003 Dec 1;124(6):714-20.

[31]. Helm S, Kreiborg S, Solow B. Malocclusion at adolescence related to selfreported tooth loss and functional disorders in adulthood. Am J Orthod. 1984 May;85(5):393-400.Pubmed PMID: 6586078.

[32]. Ngom PI, Diagne F, Benoist HM, Thiam F. Intraarch and interarch relationships of the anterior teeth and periodontal conditions. Angle Orthod. 2006 Mar;76(2):236-42.Pubmed PMID: 16539547.

[33]. Hujoel PP, Cunha-Cruz J, Loesche WJ, Robertson PB. Personal oral hygiene and chronic periodontitis: a systematic review. Periodontol 2000. 2005:37:29-34.Pubmed PMID: 15655023.

[34]. Helm S, Petersen PE. Causal relation between malocclusion and periodontal health. ActaOdontol Scand. 1989 Jan 1;47(4):223-8.

[35]. Rahbar MI, CHAUDHRY NA. DENTAL CROWDING AND ITS RELATIONSHIP TO ARCH DIMENSIONS--GENDER DIMORPHISM. Pak Oral Dental J. 2010 Dec 1;30(2).

[36]. Decusară M, Cornea D, Şincar DC, Ilie M. STATISTICAL STUDY OF DENTAL CROWDING. Romanian J Oral Rehabil. 2019 Oct;11(4). 